\title{
PROXIMITY TO DEATH AND PARTICIPATION IN THE LONG- TERM CARE MARKET
}

\author{
FRANCE WEAVER ${ }^{\mathrm{a}, *}$, SALLY C. STEARNS ${ }^{\mathrm{b}}$, EDWARD C. NORTON $^{\mathrm{c}, \mathrm{d}}$ and WILLIAM SPECTOR \\ ${ }^{\mathrm{a}}$ Swiss Health Observatory, Neuchâtel, Switzerland \\ ${ }^{\mathrm{b}}$ Department of Health Policy and Management, The University of North Carolina at Chapel Hill, Chapel Hill, NC, USA \\ ${ }^{\mathrm{c}}$ Department of Health Management and Policy, University of Michigan, Ann Arbor, MI, USA \\ ${ }^{\mathrm{d}}$ Department of Economics, University of Michigan, Ann Arbor, MI, USA \\ ${ }^{\mathrm{e}}$ Agency for Healthcare Research and Quality, Center for Delivery, Organization, and Markets, Rockville, MD, USA
}

\begin{abstract}
SUMMARY
The extent to which increasing longevity increases per capita demand for long-term care depends on the degree to which utilization is concentrated at the end of life. We estimate the marginal effect of proximity to death, measured by being within 2 years of death, on the probabilities of nursing home and formal home care use, and we determine whether this effect differs by availability of informal care - i.e. marital status and co-residence with an adult child. The analysis uses a sample of elderly aged 70+from the 1993-2002 Health and Retirement Study. Simultaneous probit models address the joint decisions to use long-term care and co-reside with an adult child. Overall, proximity to death significantly increases the probability of nursing home use by $50.0 \%$ and of formal home care use by $12.4 \%$. Availability of informal support significantly reduces the effect of proximity to death. Among married elderly, proximity to death has no effect on institutionalization. In conclusion, proximity to death is one of the main drivers of long-term care use, but changes in sources of informal support, such as an increase in the proportion of married elderly, may lessen its importance in shaping the demand for long-term care. Copyright (C) 2008 John Wiley \& Sons, Ltd.
\end{abstract}

Received 3 November 2006; Revised 7 May 2008; Accepted 11 July 2008

KEY WORDS: proximity to death; long-term care; informal care

\section{INTRODUCTION}

Concerns about the growth in long-term care expenditures have intensified over the last decade because of the aging of the baby boom generations and the ongoing increase in life expectancy (NCHS, 2003). The growing elderly population will undoubtedly increase the pool of persons in need of long-term care. However, if the use of long-term care is concentrated at the end of life, increasing longevity may not increase the per capita demand for long-term care substantially. Therefore, the overall demand for longterm care may not increase as much as anticipated by some researchers and policy makers.

A growing body of literature documents that proximity to death, rather than age, is the main determinant of acute and post-acute care expenditures at the end of life (Zweifel et al., 1999, 2004; Felder et al., 2000; Cutler and Meara, 2001; Seshamani and Gray, 2004a,b). For an overview of these studies refer to Payne et al. (2007). As elderly persons get closer to death, their use of health-care services increases, not because they become older per se but because their health deteriorates. Proximity to death captures the deterioration in health associated with the mortality process, while age and other

*Correspondence to: Swiss Health Observatory, Espace de l'Europe 10, 2010 Neuchâtel, Switzerland. E-mail: france.weaver@ bfs.admin.ch 
indicators of health status capture the health decline due to morbidity. Accounting for the effect of proximity to death results in lower estimates of future Medicare expenditures (Miller, 2001; Stearns and Norton, 2004). Disentangling the effect of proximity to death from the effect of age on the use of longterm care has received limited attention and is not well understood (Cutler and Sheiner, 1998; Yang et al., 2003; Werblow et al., 2007). The first contribution of this study is to estimate the marginal effect of proximity to death on the use of nursing home and formal (paid) in-home care to assess the extent to which increasing longevity is likely to raise individual participation in the long-term care market.

Besides health status, another major determinant of the demand for long-term care is the availability of informal care. Care provided by family members and friends is usually a substitute to nursing home and formal home care use (Lo Sasso and Johnson, 2002; Van Houtven and Norton, 2004, 2008; Charles and Sevak, 2005). Typically, the primary caregivers of married elderly are spouses, while children care for unmarried parents (Spector et al., 2000; Spillman and Pezzin, 2000). However, the availability of informal care is changing over time. Availability of spousal care is currently growing because of the documented increase in the proportion of married elderly (CPS, 2007). At the same time, support from children may be reduced due to declining fertility rates and competing demands on adult children (Pezzin and Schone, 1999; Carmichael and Charles, 2003). In the context of increasing longevity and changing informal support, we estimate the effect of proximity to death by availability and sources of informal care - i.e. by marital status and whether the elderly co-reside with an adult child. To our knowledge, this is the first study to analyze the interplay between these two major determinants of longterm care.

The probabilities of nursing home and formal home care use are estimated separately by probit models with simultaneous equations. Such simultaneous probit models provide consistent estimates when correcting for the simultaneity of multiple dichotomous decisions (Bhattacharya et al., 2006). The decision to use nursing home care is modeled as being determined simultaneously with the decision to co-reside with an adult child and the decision to co-reside interacted with proximity to death. A similar simultaneous estimation is conducted for the probability of formal home care use. The estimates provide insight into the interaction between some of the most important factors affecting future longterm care use.

\section{BACKGROUND}

Health-care expenditures increase substantially in the last years of life and with age at death (Lubitz et al., 1995; Spillman and Lubitz, 2000, 2002). However, the pattern of use before death differs for acute care and long-term care. Spillman and Lubitz (2000) show that hospital and physician expenditures increase at a decreasing rate and nursing home expenditures increase at an accelerating rate with age at death. One limitation of these studies is that they do not separate the effect of age from the effect of proximity to death. The increase in use of health-care services may not be due to the aging of the population per se, but to the fact that utilization is concentrated at the end of life. Disentangling these two phenomena is particularly important in the context of increasing longevity. If life expectancy remains constant, age can be used by itself to consistently estimate the demand for long-term care. If life expectancy increases over time, as observed over the last decades, omitting proximity to death overestimates the effect of age and therefore the predictions of future health-care expenditures (Miller, 2001; Stearns and Norton, 2004).

\subsection{Proximity to death and long-term care use}

Evidence of the effects of age and proximity to death on long-term care use is limited (Cutler and Sheiner, 1998; Yang et al., 2003; Werblow et al., 2007). Estimating a linear probability model on the 1992 Medicare Current Beneficiary Survey, Cutler and Sheiner (1998) find that being within 2 years of 
death has a positive and significant effect on the probability of nursing home use. The impact of age on institutionalization diminishes considerably once controlling for proximity to death. Yang et al. (2003) conduct a graphical analysis and illustrate that Medicaid and nursing home expenditures increase steadily with age, regardless of proximity to death. Home health expenditures increase slightly with age and time to death. Using Swiss data, Werblow et al. (2007) find that aging may increase long-term care expenditures, even after controlling for proximity to death. These studies either rely on old data (from 1992 for Cutler and Sheiner, 1998), rely on a purely descriptive analysis (Yang et al., 2003), or have incomplete empirical models (Cutler and Sheiner, 1998; Werblow et al., 2007). None of these studies has been able to address the potential endogeneity of proximity to death.

Not only is life expectancy increasing but disability, a major determinant of long-term care use, is also changing over time (Manton et al., 1998; Lakdawalla et al., 2003; Manton, 2003). Some studies show that disability and time to death have independent effects on acute and long-term care expenditures, while age has either a small effect or is not significant (Cutler and Sheiner, 1998; Cutler and Meara, 2001; Stearns et al., 2007). In all three studies, the conclusion is the same regardless of the type of expenditures: the effect of age diminishes considerably when controlling for disability and time to death. These three measures capture different dimensions of health deterioration. Proximity to death may reflect irreversible degradation in the physiological functions when approaching death. Disability, traditionally measured by limitations in activity of daily living (ADL) and instrumental activity of daily living (IADL), depicts chronic dimensions of the deterioration in health, which are not experienced by all individuals. Such morbidity process may or may not be related to the mortality process. Once the mortality and morbidity processes are controlled for, age captures any remaining needs related to aging itself. The present study determines whether proximity to death significantly increases the likelihood of participating in the long-term care market, when controlling for age and disability severity.

\subsection{Sources of informal home care and proximity to death}

In the long-term care literature, separate attention is usually paid to the effects of aging (Lubitz et al., 2003; Dormont et al., 2006) and informal care (Lo Sasso and Johnson, 2002; Charles and Sevak, 2005; Van Houtven and Norton, 2004, 2008). In the present study, we look at the interplay between some dimensions of these two major determinants of nursing home and formal home care use. Because informal care is typically a substitute to nursing home and formal home care use, we hypothesize that availability of informal support mitigates the effect of proximity to death. Stated differently, the effect of proximity to death is expected to be smaller among married elderly and the elderly co-residing with an adult child than among non-married elderly

The effects of availability of informal care on formal long-term care use may depend on the relationship between the caregivers and the elderly persons (Norton, 2000). Freedman (1996) shows that being married reduces the likelihood of institutionalization more than having a daughter as caregiver. Newman and Struyk (1990) document that help provided by a spouse is associated with a lower risk of institutionalization, while help from other person's results in a higher likelihood of nursing home use. Such differences can be explained by different opportunity costs for retired spouses and middle-aged children who are still part of the work force, distinct motivations and social justifications to provide care for spouses and children, or by different preferences of the care providers and recipients. Therefore, the effect of proximity to death may differ whether spousal care or support from children is available.

In this study, availability of spousal care is measured by marital status and availability of informal care from children is measured by co-residence with an adult child. This latter indicator is selected for two reasons. First, the decision to move in with an aging parent, or to have an elderly parent move in with a child, is often motivated by the need to supervise and provide some support to that aging person. In that regard, co-residence with an adult child is a less noisy indicator of available support from children than other potential measures, such as having children living close by. Second, such living 
arrangement is comparable to being married to the extent that in both cases the potential caregiver resides with the elderly person.

\subsection{Hypotheses}

The two main contributions of this study are (i) to disentangle the effect of age, disability and proximity to death on the likelihood of long-term care use; and (ii) to document the interplay between two major determinants of long-term care use: proximity to death and sources of informal support. To summarize, this study tests three hypotheses:

1. Proximity to death increases the probability of institutionalization and the probability of formal home care use.

2. Proximity to death has a smaller effect among married elderly and those co-residing with an adult child than among non-married elderly without a co-residing child.

3. The effect of proximity to death differs by source of informal support, i.e. married elderly and the ones residing with an adult child.

We do not hypothesize a priori the relative differences in the effect of proximity to death by type of informal support (hypothesis 3) because the evidence in the literature is limited and the theory is not well developed. Estimates of the relative differences in effect are therefore an empirical contribution of this work.

In hypothesis 2, we focus solely on the interaction between the mortality process, captured by proximity to death, and availability of informal care. Conceptually, other interactions would be of interest, such as between proximity to death and age (Stearns et al., 2007) or between the morbidity process (disability) and availability of informal care. Adding such interactions is beyond the scope of the present paper and raises empirical issues, such as multicollinearity.

\section{METHODS}

\subsection{Empirical model}

To test these hypotheses, we use panel data to estimate two separate models: the probability of institutionalization and the probability of formal home care use. The dependent variables are dichotomous indicators of whether individual $i$ is institutionalized or has any formal home care use at the time of interview $t\left(\operatorname{Pr}\left[Y_{i t}=1\right]\right)$. The formal home care model is conditional on residing in the community, as opposed to being institutionalized. We rely on interaction terms to test whether the effect of proximity to death differs by availability and sources of informal support. Specifically, these two models are specified as functions of proximity to death $\left(\mathrm{PTD}_{i t}\right)$, its interaction with being married $\left(\mathrm{PTD}_{i t} \times \operatorname{Married}_{i t}\right)$ and co-residing with an adult child $\left(\mathrm{PTD}_{i t} \times \mathrm{Rchild}_{i t}\right)$, age, and other explanatory variables correlated with the variables of interest and long-term care use:

$$
\begin{aligned}
\operatorname{Pr}\left[Y_{i t}=1\right]= & \alpha_{0}+\alpha_{1} \text { PTD }_{i t}+\alpha_{2} \text { PTD }_{i t} \times \text { Married }_{i t}+\alpha_{3} \text { PTD }_{i t} \times \operatorname{Rchild}_{i t} \\
& +\alpha_{4} \text { Married }_{i t}+\alpha_{5} \text { Rchild }_{i t}+\alpha_{6} \text { Age }_{i t}+\alpha_{7} \text { Controls }_{i t}+\epsilon_{i t}
\end{aligned}
$$

Proximity to death is measured by a dichotomous indicator of whether the person is within 2 years of death at the time of each interview. The literature documents that the use of health-care services increases the most in the last 2 years of life (Seshamani and Gray, 2004a,b; Lubitz et al., 1995; Yang et al., 2003). Furthermore, such a time frame minimizes the number of missing observations. In the 
Health and Retirement Study (HRS), the interviews occur every 2 years. When the date of death is unavailable $(n=991)$, the vital status at the next interview indicates whether an individual is deceased.

Married elderly also include the elderly living with a partner without being legally married. These cohabiting elderly represent a very small fraction of our sample and the results reported below are not sensitive to including cohabiting elderly in the Married variable. Age has a quadratic form to capture potential nonlinear effects. The control variables (Controls $i t)$ include the following factors. Disability is measured by having difficulties with ADLs and IADLs. Two sets of three dichotomous variables indicate the number of limitations: 1 ADL, 2-3 ADLs, 4-5 ADLs, with no ADL as reference category, and similarly for the number of IADLs. The cognitive level of the participants is assessed by a set of 10 questions testing their memory ability. Low cognition is defined as having five or fewer correct answers. The socioeconomic characteristics are being African American, having less than a high school degree, and net wealth represented by a set of categorical variables $(\leq 1000 ; 1001-20000 ; 20001-200000$; $200001-500000$ and above 500000 as reference). The health insurance indicators are Medicaid coverage and having long-term care insurance. Living arrangements are controlled for by whether the person resides in a senior housing or a retirement community and whether any child lives within 10 miles. These two variables can also be considered as indicators of the availability of paid and informal home care. The geographic variables are urban and suburban indicators. Time fixed effects (FE) adjust for changes in the long-term care market in the 1990s, such as the changes in Medicare home health reimbursement and the expansion in Medicaid home and community-based services. The error term $\left(\varepsilon_{i t}\right)$ captures any remaining unobserved heterogeneity.

\subsection{Endogeneity}

Two variables of interest may be endogenous to the participation in the long-term care market: proximity to death and residing with an adult child. With respect to proximity to death, some argue that using long-term care may lengthen life. Holding other characteristics constant, nursing home residents may live longer than the elderly living at home because they benefit from closer supervision. Nevertheless, the opposite may apply: once institutionalized, the elderly persons may lose interest in life and die faster than if they remained in the community. Furthermore, unobserved individual characteristics may influence both proximity to death and long-term care use. For example, having a healthy life style - e.g. exercising and having a balanced diet - may not only lengthen life but also reduce the use of health-care services.

Zweifel et al. (2004) tried to address the endogeneity of time to death in a model of health-care expenditures. They adopt what they call a 'quasi-instrumental variables' strategy, by controlling for lagged health-care expenditures in their main equations. Their finding that proximity to death, rather than age, is the main determinant of health-care expenditures is robust to endogeneity error. Nevertheless, the authors point out that their instruments are likely to be invalid because they are correlated with unmeasured characteristics.

In the present study, no valid instrumental variables were found for proximity to death (examples of tested instruments: ages at death of the interviewee's mother and father, childhood socioeconomic status, medical conditions not related to long-term care use). Furthermore, nonlinear individual fixed effect models that would account for part of the endogeneity cannot be estimated because the probabilities of institutionalization and formal home care use are low (Greene, 2003; Bhattacharya et al., 2006). However, we estimated linear probability models with and without individual FE to observe the impact of adjusting for time-invariant unobserved person-level heterogeneity, such as family and individual preferences, or attitude toward risks. Controlling for such unobserved factors reduces the risk of omitted variable bias and endogeneity because the error term of the main equation may not be correlated with both the key variables of interest and the likelihood of long-term care use. The coefficients on proximity to death are larger when adjusting for individual FE. These results (available 
on request) indicate that not adjusting for such heterogeneity provides conservative estimates because the coefficients of interest are smaller than they would be if we could take full advantage of the panel data. However, such linear probability models predict out of the $[0,1]$ range and produce biased estimates (Bhattacharya et al., 2006).

The second variable of interest that is endogenous to long-term care use is co-residence with an adult child. An adult child may move in with a parent whose health is deteriorating to provide help with everyday needs. In that context, decisions about co-residence and long-term care use are made jointly. Furthermore, unobserved individual and family characteristics may affect both living and care arrangements. For example, the sense of responsibility and duties toward the elderly may vary across cultural or ethnic groups. Unobserved attitudes and beliefs not only affect the likelihood of a child living with an aging parent but also the type of long-term care received by that parent. An instrumental variable strategy is adopted to correct for the endogeneity of co-residing with an adult child.

Some of the control variables, such as Medicaid coverage or residing in a retirement community, may also be endogenous to the long-term care decisions. We include them in our models to reduce the potential for omitted variable bias under the assumption that the bias from endogeneity is small.

\subsection{Estimation strategy}

We estimate simultaneous equations because the decision to reside with an adult child is likely to be made jointly with the decision to participate or not in the long-term care market. Furthermore, because residing with an adult child is interacted with proximity to death; we estimate three equations simultaneously. For example, in the nursing home model, we estimate jointly:

(1) the likelihood of institutionalization $\operatorname{Pr}\left[Y_{i t}=1\right]$ - this dependent variable has a value of 1 when the person resides in a nursing home, 0 otherwise;

(2) the likelihood of co-residing with an adult child $\operatorname{Pr}\left[\mathrm{RCHILD}_{i t}=1\right]$ - this dependent variable has a value of 1 when the survey individual co-resides or used to co-reside with an adult child, 0 otherwise;

(3) the likelihood of co-residing with an adult child interacted with proximity to death $\operatorname{Pr}\left[\left(\mathrm{PTD}_{i t} \times \mathrm{RCHILD}_{i t}\right)=1\right]-$ this dependent variable has a value of 1 if the person co-resides with an adult child and is in her last 2 years of life (double condition), 0 otherwise.

For identification purposes, we need instrumental variables that predict co-residence with an adult child and its interaction with proximity to death, but do not predict the participation in the long-term care market. Equations (2) and (3) contain all the right-hand side variables of the main equation of interest (1), plus instrumental variables, which do not enter into the main Equation (1). Following Wooldridge (2002), the same instruments are used in Equations (2) and (3).

We use instruments similar to those found in the literature on informal home care: characteristics of the children of the elderly participants (Checkovich and Stern, 2002; Van Houtven and Norton, 2004, 2008; Charles and Sevak, 2005). It is well known that daughters are more likely to be caregivers than sons and birth order may also matter. We therefore use the number of daughters and whether the oldest child is a daughter as instrumental variables. The number of grandchildren may also affect co-residence with an adult child, either because of competing demands on adult children or as a measure of family values and communality. The age of the oldest adult child is also used to predict co-residence because it may capture the ability to co-reside with a frail parent. According to Wooldridge (2002), an endogenous variable appearing in an interaction term comes with its own instruments, which are the instruments for the endogenous variable (here the instruments for co-residence with an adult child) interacted with the other variable entering in the interaction (here proximity to death). Given the available instruments, the equations representing nursing home or formal home care use are overidentified. 
For each type of care, we report both the standard single-equation probit model and the simultaneous probit model to illustrate the impact of adjusting for the endogeneity of co-residing with an adult child on the estimates of interest. Standard errors are adjusted for heteroskedasticity and individual level clustering. The magnitude and significance level of proximity to death by sub-group is difficult to determine directly from the coefficients because we estimate nonlinear models with multiple interaction terms (Ai and Norton, 2003; Norton et al., 2004). Thus, we rely on the bootstrap technique to determine the statistical significance and the marginal effect of proximity to death. First, we report the overall marginal effects of proximity to death and age. We then present the marginal effect of proximity to death separately for non-married, married, and elderly who co-residing with an adult child, holding other characteristics constant. Being married and co-residing with an adult child are not mutually exclusive categories. Consequently, the marginal effect of proximity to death among married elderly is predicted holding the co-residence with an adult child constant and vice versa. Similarly, in the formal home care model, we estimate jointly the likelihood of having any formal home care use with the Equations (2) and (3) above.

We estimate the two simultaneous probit models by the method of simulated maximum likelihood. In that context, non-concavities and non-convergence are common issues, especially in models with interactions terms that are collinear. In this model, there is no serious multicollinearity between the control variables and the key variables of interest (correlations are below 0.3). Following Cappellari and Jenkins (2006), we experimented with different starting values and convergence algorithms to achieve stable results despite the use of interactions.

Finally, we test the robustness of our results to the measure of proximity to death by running the same models using a shorter time to death indicator of 'being within 1 year of death' instead of 'being within 2 years of death'.

\section{DATA}

The analysis is conducted on panel data from the HRS from 1993 to 2002. In the present study, two cohorts of participants are used. The Asset and Health Dynamics Among the Oldest-Old (AHEAD) sampled people aged 70+, and their spouses and partners, in 1993. This cohort was surveyed separately from 1993 to 1998 when it was merged with the HRS. The Children of the Depression (CODA) cohort was added to the HRS in 1998 and includes participants born between 1924 and 1930. The baseline samples are restricted to elderly living in the community, but the residential status of the respondents is not a criterion in subsequent waves. Because the baseline samples do not include institutionalized elderly, they represent a healthier group than the overall elderly population.

Proximity to death is a retrospective measure of whether the respondent is within 2 years of death at the time of each interview. This indicator is based on the month and year of death from National Death Index . Because the interview day is available only in 1993, we assume that both the interviews and dates of death occurred on the 15 th of the month. Doing so minimizes errors and allows us to determine the number of days between each interview and death. The 2002 data are used to determine only who died since the 2000 interview, but observations from the 2002 wave are not used in the regression analysis.

Our sample includes all HRS participants and spouses aged 70 and over at baseline: the sample contains 7443 AHEAD participants in 1993 and 1553 CODA participants in 1998. Spouses or partners younger than 70 are excluded from the analysis. The restriction of the analysis to person's age 70 or older occurs primarily because the HRS did not sample people under age 70, but the restriction is reasonable because long-term care use tends to occur at advanced ages (Spector et al., 2000). The attrition over time is mainly due to mortality. Between two consecutive waves, the hazard rate of death varies between 10.6 and $16.6 \%$ for the AHEAD cohort and between 4.2 and $6.5 \%$ for the younger CODA cohort. Missing data, primarily on co-residence with adult children, results in dropping $7.3 \%$ of 
the observations. The regression analysis is conducted on four waves of data (1993, 1995, 1998 and 2000), while the 2002 observations help determine whether the persons surveyed in 2000 die within 2 years. The final sample has 23534 observations and is used to estimate the model of the likelihood of nursing home use. Some $3.6 \%$ of these observations correspond to institutionalized participants at the time of the interview, leaving a community-based sample of 22684 observations for estimation of the formal home care model. This community sample includes persons living in assisted living or senior housing facilities.

The participants are on average 78.8 years old with the youngest person being 70 and the oldest 107 years old. About $75 \%$ of the person-wave observations do not have any difficulties with IADLs and $76 \%$ do not have any difficulties with ADLs. The most disabled persons, who report 4-5 ADL limitations, represent $5.5 \%$ of the observations. Low cognition is more prevalent at $15.1 \%$. Males account for $39.4 \%$ of the observations, African American for $12 \%$, and nearly $43 \%$ did not graduate from high school. The mean net wealth is $\$ 165230$, for a median of $\$ 80500$. Medicaid covers about $10.3 \%$ of the sample at some point, and roughly $10 \%$ has long-term care insurance. About $6 \%$ lives in a retirement community or senior housing, and more than half of the sample has children living within 10 miles at some point during the survey. Urban and suburban residents represent 45 and $29 \%$, respectively.

Persons approaching death are more likely to use long-term care than those further away from death (Table I). Some $14.6 \%$ of the persons in their last 2 years of life reside in institution, compared with $2 \%$ of the people further away from death. Similarly, $14.7 \%$ of community residents within 2 years of death use formal home care, compared with $3.9 \%$ of those further away from death. Availability of informal care also differs by proximity to death. Married elderly account for $39.5 \%$ of the persons in their last 2 years of life while they represent $48.8 \%$ of the persons not close to death. Some $19.9 \%$ of the persons in their last 2 years of life reside with an adult child at some point, compared with $15.9 \%$ of those further away from death. As expected, these proportions are higher when considering the community dwellers only.

\section{RESULTS}

\subsection{Specification tests on instrumental variables}

Table II provides results from specification tests. The set of instruments that performs the best in the nursing home model are the number of daughters, the number of grandchildren, the age of the oldest child and whether the oldest child is a daughter interacted with proximity to death. In the formal home care model, the valid instruments are the number of grandchildren, whether the oldest child

Table I. Distribution of variables of interest by proximity to death

\begin{tabular}{|c|c|c|c|c|}
\hline & \multicolumn{2}{|c|}{ Entire sample $(N=23534)$} & \multicolumn{2}{|c|}{ Community-based sample $(N=22684)$} \\
\hline & $\begin{array}{l}\text { Within } 2 \text { years of } \\
\text { death }(N=2914)\end{array}$ & $\begin{array}{l}\text { Not in } 2 \text { years of } \\
\text { death }(N=20620)\end{array}$ & $\begin{array}{l}\text { Within } 2 \text { years of } \\
\text { death }(N=2487)\end{array}$ & $\begin{array}{r}\text { Not in } 2 \text { years of } \\
\text { death }(N=20197)\end{array}$ \\
\hline Institutionalized & $\begin{array}{c}427 \\
(14.65)^{\mathrm{a}}\end{array}$ & $\begin{array}{c}423 \\
(2.05)\end{array}$ & - & - \\
\hline Home care user & - & - & $\begin{array}{c}366 \\
(14.72)\end{array}$ & $\begin{array}{c}794 \\
(3.93)\end{array}$ \\
\hline Married & $\begin{array}{c}1151 \\
(39.50)\end{array}$ & $\begin{array}{c}10062 \\
(48.80)\end{array}$ & $\begin{array}{l}1118 \\
(44.95)\end{array}$ & $\begin{array}{l}10015 \\
(49.59)\end{array}$ \\
\hline Reside with child & $\begin{array}{c}580 \\
(19.90)\end{array}$ & $\begin{array}{c}3281 \\
(15.91)\end{array}$ & $\begin{array}{c}545 \\
(21.91)\end{array}$ & $\begin{array}{c}3254 \\
(16.11)\end{array}$ \\
\hline
\end{tabular}

${ }^{\mathrm{a}}$ The percentages in parentheses are based on the number of observations in each column. 
Table II. Specification tests on instrumental variables

\begin{tabular}{|c|c|c|c|c|}
\hline \multirow[b]{2}{*}{ Model } & \multicolumn{2}{|c|}{ Strength of instruments } & \multirow[t]{2}{*}{ Overidentification test ${ }^{\mathrm{a}}$} & \multirow[t]{2}{*}{ Exogeneity test } \\
\hline & $\mathrm{RCHILD}_{i t}$ & $\mathrm{PTD}_{i t} \times \mathrm{RCHILD}_{i t}$ & & \\
\hline $\begin{array}{l}\text { Formal home care } \\
\text { Nursing home }^{\mathrm{c}}\end{array}$ & $\begin{array}{l}\chi^{2}(4)=371.47^{* * *} \\
\chi^{2}(4)=146.77^{* * *}\end{array}$ & $\begin{array}{l}\chi^{2}(4)=704.18^{* * *} \\
\chi^{2}(4)=3326.42^{* * *}\end{array}$ & $\begin{array}{l}\chi^{2}(4)=6.64 \\
\chi^{2}(4)=3.20\end{array}$ & $\begin{array}{l}\chi^{2}(2)=8.69^{* *} \\
\chi^{2}(2)=3.39\end{array}$ \\
\hline
\end{tabular}

is a daughter and their interaction with proximity to death. The $\chi^{2}$ tests indicate that for both types of care, the identifying instruments are strong predictors of co-residence with an adult child and its interaction with proximity to death. Overidentification tests, consisting of Wald tests on the instruments when included in the main equations, show that the instruments are also validly excluded from the main equations. Finally, the Rivers-Vuong exogeneity tests detect that residing with an adult child is endogenous to formal home care use but is exogenous to nursing home use (Rivers and Vuong, 1988). Because the decisions to co-reside with an adult child and use long-term care are theoretically made simultaneously, we account for this endogeneity by using the simultaneous probit models to determine the marginal effect of proximity to death.

\subsection{Empirical models}

Adjusting for the simultaneity of the living and care arrangement enlarges the effect of the two endogeneous variables: co-residing with an adult child and its interaction with proximity to death. However, the simultaneity adjustment has a limited effect on the other variables: the significance levels and magnitude of the coefficients are comparable in the single-equation probit and simultaneous probit models (Table III). In both the nursing home and formal home care models, the variables of interest have the expected sign: positive on proximity to death and negative on being married, co-residing with an adult child (see Table III).

The likelihood of institutionalization significantly increases with age but at a decreasing rate, as indicated by the positive coefficient on age and the negative coefficient on age squared. Age has a similar effect on the likelihood of formal home care use, as age and age squared are jointly significant $\left(\chi^{2}(2)=34.33, p<0.01\right)$. As expected, the more disabled the person, the higher the probabilities of having any nursing home stay or any use of formal home care. Low cognition significantly increases the likelihood of institutionalization, but not formal home care use. Being a male, having low wealth and being covered by Medicaid significantly increase the probability of being institutionalized, while being African American, low education or living in a retirement community significantly reduce this probability. The effects of some of these variables differ in the formal home care model. The probability is lower if the person is male, has low wealth or resides in a suburban area. The probability is higher if the person is covered by Medicaid or resides in a retirement community.

\subsection{Overall effects of proximity to death and age}

As mentioned previously, we bootstrap the simultaneous probit models to predict the marginal effect of proximity to death and get consistent estimates of the standard errors. Overall, holding all characteristics constant (including marital status and co-residence with an adult child), being within 2 years of death significantly $(p<0.01)$ increases the probabilities of nursing home and formal home care use (Table IV). The marginal effect of proximity to death is larger for nursing home than formal home care, both in absolute terms (percentage point increase) and relative terms (percent increase). The 
Table III. Nonlinear models

\begin{tabular}{|c|c|c|c|c|}
\hline \multirow[b]{2}{*}{ Variables } & \multicolumn{2}{|c|}{ Nursing home use $(N=23534)$} & \multicolumn{2}{|c|}{ Formal home care use ${ }^{\mathrm{a}}(N=22684)$} \\
\hline & Single probit & Simultaneous probit ${ }^{\mathrm{b}}$ & Single probit & Simultaneous probit ${ }^{\mathrm{b}}$ \\
\hline \multicolumn{5}{|l|}{ Variables of interest } \\
\hline Die in 2 years & $\begin{array}{c}0.510^{* * *} \\
(0.057)\end{array}$ & $\begin{array}{c}0.5252^{* * * *} \\
(0.638)\end{array}$ & $\begin{array}{c}0.191^{* * *} \\
(0.067)\end{array}$ & $\begin{array}{c}0.2191^{* * * *} \\
(0.0739)\end{array}$ \\
\hline Married $\times$ die in 2 years & $\begin{array}{c}-0.488^{* * * *} \\
(0.136)\end{array}$ & $\begin{array}{c}-0.4924^{* * *} \\
(0.1149)\end{array}$ & $\begin{array}{l}-0.081 \\
(0.101)\end{array}$ & $\begin{array}{l}-0.0992 \\
(0.1095)\end{array}$ \\
\hline Res. child $\times$ die in 2 years & $\begin{array}{l}-0.178 \\
(0.157)\end{array}$ & $\begin{array}{l}-0.2387 \\
(0.1905)\end{array}$ & $\begin{array}{l}-0.010 \\
(0.115)\end{array}$ & $\begin{array}{l}-0.0560 \\
(0.1399)\end{array}$ \\
\hline Married & $\begin{array}{c}-0.617^{* * * *} \\
(0.083)\end{array}$ & $\begin{array}{c}-0.6304^{* * *} \\
(0.0738)\end{array}$ & $\begin{array}{c}-0.328^{* * * *} \\
(0.066)\end{array}$ & $\begin{array}{c}-0.3430^{* * *} \\
(0.0618)\end{array}$ \\
\hline Resident child & $\begin{array}{c}-1.148^{* * * *} \\
(0.118)\end{array}$ & $\begin{array}{c}-1.3330^{* * *} \\
(0.3813)\end{array}$ & $\begin{array}{c}-0.409^{* * * *} \\
(0.075)\end{array}$ & $\begin{array}{c}-0.5867^{* *} \\
(0.2409)\end{array}$ \\
\hline Age & $\begin{array}{c}0.198^{* *} \\
(0.080)\end{array}$ & $\begin{array}{c}0.1866^{* * *} \\
(0.0677)\end{array}$ & $\begin{array}{c}0.108) \\
(0.067)\end{array}$ & $\begin{array}{c}0.0878 \\
(0.0742)\end{array}$ \\
\hline Age squared & $\begin{array}{c}-0.001^{* *} \\
(0.001)\end{array}$ & $\begin{array}{c}-0.0009^{* *} \\
(0.0004)\end{array}$ & $\begin{array}{l}-0.001 \\
(0.000)\end{array}$ & $\begin{array}{l}-0.0004 \\
(0.0004)\end{array}$ \\
\hline \multicolumn{5}{|l|}{ Disability } \\
\hline $1 \mathrm{IADL}$ & $\begin{array}{c}0.125 \\
(0.082)\end{array}$ & $\begin{array}{c}0.1330 \\
(0.0862)\end{array}$ & $\begin{array}{c}1.107^{* * *} \\
(0.068)\end{array}$ & $\begin{array}{c}1.1092^{* * *} \\
(0.7345)\end{array}$ \\
\hline 2-3 IADLs & $\begin{array}{c}0.373^{* * *} \\
(0.082)\end{array}$ & $\begin{array}{c}0.3861^{* * *} * \\
(0.0857)\end{array}$ & $\begin{array}{c}1.547^{* * *} \\
(0.073)\end{array}$ & $\begin{array}{c}1.5543^{* * *} \\
(0.0776)\end{array}$ \\
\hline 4-5 IADLs & $\begin{array}{c}0.853^{* * *} \\
(0.089)\end{array}$ & $\begin{array}{c}0.8680^{* * * *} \\
(0.1048)\end{array}$ & $\begin{array}{c}1.886^{* * *} \\
(0.093)\end{array}$ & $\begin{array}{c}1.9062^{* * *} \\
(0.0962)\end{array}$ \\
\hline $1 \mathrm{ADL}$ & $\begin{array}{c}0.159^{* *} \\
(0.077)\end{array}$ & $\begin{array}{l}0.1600^{*} \\
(0.0840)\end{array}$ & $\begin{array}{c}0.459^{* * *} \\
(0.059)\end{array}$ & $\begin{array}{c}0.4605^{* * *} \\
(0.0360)\end{array}$ \\
\hline 2-3 ADLs & $\begin{array}{c}0.365^{* * *} \\
(0.078)\end{array}$ & $\begin{array}{c}0.3610^{* * * *} \\
(0.0836)\end{array}$ & $\begin{array}{c}0.750^{* * *} \\
(0.059)\end{array}$ & $\begin{array}{c}0.7438^{* * * *} \\
(0.0559)\end{array}$ \\
\hline 4-5 ADLs & $\begin{array}{c}0.668^{* * *} \\
(0.084)\end{array}$ & $\begin{array}{c}0.6580^{* * * *} \\
(0.0509)\end{array}$ & $\begin{array}{c}1.061^{* * *} \\
(0.072\end{array}$ & $\begin{array}{c}1.0566^{* * * *} \\
(0.0661)\end{array}$ \\
\hline Low cognition & $\begin{array}{c}0.732^{* * *} \\
(0.063)\end{array}$ & $\begin{array}{c}0.7385^{* * *} \\
(0.0551)\end{array}$ & $\begin{array}{l}-0.055 \\
(0.055)\end{array}$ & $\begin{array}{l}-0.0422 \\
(0.0617)\end{array}$ \\
\hline \multicolumn{5}{|l|}{ Other control variables } \\
\hline Male & $\begin{array}{l}0.100^{*} \\
(0.061)\end{array}$ & $\begin{array}{c}0.0970^{* *} \\
(0.0436)\end{array}$ & $\begin{array}{c}-0.200^{* * *} \\
(0.056)\end{array}$ & $\begin{array}{c}-0.2010^{* * *} \\
(0.0501)\end{array}$ \\
\hline African American & $\begin{array}{c}-0.331^{* * * *} \\
(0.081)\end{array}$ & $\begin{array}{c}-0.3098^{* * *} \\
(0.0967)\end{array}$ & $\begin{array}{l}-0.059 \\
(0.068)\end{array}$ & $\begin{array}{l}-0.0443 \\
(0.0635)\end{array}$ \\
\hline Less than high school & $\begin{array}{c}-0.322^{* * * *} \\
(0.059)\end{array}$ & $\begin{array}{c}-0.3105^{* * *} \\
(0.0615)\end{array}$ & $\begin{array}{c}-0.087^{*} \\
(0.052)\end{array}$ & $\begin{array}{l}-0.0760 \\
(0.0561)\end{array}$ \\
\hline Medicaid & $\begin{array}{c}0.284^{* * *} \\
(0.063)\end{array}$ & $\begin{array}{c}0.2790^{* * *} \\
(0.0734)\end{array}$ & $\begin{array}{c}0.438^{* * *} \\
(0.059)\end{array}$ & $\begin{array}{c}0.4353^{* * *} \\
(0.0553)\end{array}$ \\
\hline LTC insurance & $\begin{array}{c}0.042 \\
(0.101)\end{array}$ & $\begin{array}{c}0.0345 \\
(0.0746)\end{array}$ & $\begin{array}{l}-0.036 \\
(0.080)\end{array}$ & $\begin{array}{l}-0.0427 \\
(0.0657)\end{array}$ \\
\hline Wealth $\Leftarrow 1000$ & $\begin{array}{c}0.432^{* * * *} \\
(0.119)\end{array}$ & $\begin{array}{c}0.4514^{* * *} \\
(0.0912)\end{array}$ & $\begin{array}{c}-0.196^{*} \\
(0.103)\end{array}$ & $\begin{array}{r}-0.1735^{*} \\
(0.0935)\end{array}$ \\
\hline Wealth 1001-2000 & $\begin{array}{c}0.321^{* * *} \\
(0.114)\end{array}$ & $\begin{array}{c}0.3321^{* * *} \\
(0.1151)\end{array}$ & $\begin{array}{c}-0.171^{*} \\
(0.097)\end{array}$ & $\begin{array}{r}-0.1577^{*} \\
(0.0928)\end{array}$ \\
\hline Wealth $20001-200000$ & $\begin{array}{c}0.036 \\
(0.104)\end{array}$ & $\begin{array}{c}0.0431 \\
(0.1155)\end{array}$ & $\begin{array}{c}-0.229^{* * * *} \\
(0.085)\end{array}$ & $\begin{array}{c}-0.2223^{* * *} \\
(0.0802)\end{array}$ \\
\hline Wealth $200001-500000$ & $\begin{array}{c}0.012 \\
(0.115)\end{array}$ & $\begin{array}{c}0.0129 \\
(0.1500)\end{array}$ & $\begin{array}{c}-0.177^{* *} \\
(0.090)\end{array}$ & $\begin{array}{c}-0.1774^{* * *} \\
(0.0746)\end{array}$ \\
\hline Live in retir. community & $\begin{array}{c}-0.654^{* * * *} \\
(0.135)\end{array}$ & $\begin{array}{c}-0.7003^{* * *} \\
(0.1370)\end{array}$ & $\begin{array}{c}0.394^{* * *} \\
(0.069)\end{array}$ & $\begin{array}{c}0.3437^{* * *} \\
(0.1010)\end{array}$ \\
\hline Child within 10 miles & $\begin{array}{c}0.074 \\
(0.052)\end{array}$ & $\begin{array}{l}0.0305^{*} \\
(0.0324)\end{array}$ & $\begin{array}{l}-0.073 \\
(0.045)\end{array}$ & $\begin{array}{c}-0.0816^{* *} \\
(0.0409)\end{array}$ \\
\hline Urban residence & $\begin{array}{c}0.023 \\
(0.063)\end{array}$ & $\begin{array}{c}0.0370 \\
(0.0464)\end{array}$ & $\begin{array}{l}-0.058 \\
(0.054)\end{array}$ & $\begin{array}{l}-0.0442 \\
(0.0483)\end{array}$ \\
\hline Suburban residence & $\begin{array}{c}0.046 \\
(0.067)\end{array}$ & $\begin{array}{c}0.0534 \\
(0.0657)\end{array}$ & $\begin{array}{c}-0.146^{* *} \\
(0.060)\end{array}$ & $\begin{array}{c}-0.1350^{* * *} \\
(0.0539)\end{array}$ \\
\hline
\end{tabular}


Table III. Continued.

\begin{tabular}{|c|c|c|c|c|}
\hline \multirow[b]{2}{*}{ Variables } & \multicolumn{2}{|c|}{ Nursing home use $(N=23534)$} & \multicolumn{2}{|c|}{ Formal home care use $^{\mathrm{a}}(N=22684)$} \\
\hline & Single probit & Simultaneous probit ${ }^{\mathrm{b}}$ & Single probit & Simultaneous probit ${ }^{\mathrm{b}}$ \\
\hline 1995 & $-^{\mathrm{c}}$ & $-^{\mathrm{c}}$ & $\begin{array}{l}-0.061 \\
(0.053)\end{array}$ & $\begin{array}{l}-0.0586 \\
(0.0737)\end{array}$ \\
\hline 1998 & $\begin{array}{c}0.540^{* * *} \\
(0.052)\end{array}$ & $\begin{array}{c}0.5356^{* * * *} \\
(0.0747)\end{array}$ & $\begin{array}{l}0.121^{* *} \\
(0.052)\end{array}$ & $\begin{array}{l}0.1208^{*} \\
(0.0634)\end{array}$ \\
\hline 2000 & $\begin{array}{c}0.556^{* * *} \\
(0.057)\end{array}$ & $\begin{array}{c}0.5498^{* * *} \\
(0.0652)\end{array}$ & $\begin{array}{l}0.059^{*} \\
(0.056)\end{array}$ & $\begin{array}{c}0.0613 \\
(0.0596)\end{array}$ \\
\hline Constant & $\begin{array}{c}-12.510^{* * *} \\
(3.384)\end{array}$ & $\begin{array}{c}-11.9664^{* * *} \\
(2.9000)\end{array}$ & $\begin{array}{c}-7.400^{* * * *} \\
(2.770)\end{array}$ & $\begin{array}{c}-6.7883^{* *} \\
(3.0889)\end{array}$ \\
\hline Log pseudo-likelihood & -1816.91 & -1553.81 & -2521.49 & -11565.81 \\
\hline Wald $\chi^{2}(29 / 30)$ & 1765.00 & 2064.81 & 2910.78 & 8646.16 \\
\hline Correlation $21^{\mathrm{d}}$ & & $\begin{array}{c}0.1160 \\
(0.1825)\end{array}$ & & $\begin{array}{c}0.1156 \\
(0.1609)\end{array}$ \\
\hline Correlation $31^{\mathrm{e}}$ & & $\begin{array}{c}0.1471 \\
(0.2157)\end{array}$ & & $\begin{array}{c}0.1557 \\
(0.2016)\end{array}$ \\
\hline Pseudo $R$ square & 0.50 & - & 0.45 & - \\
\hline
\end{tabular}

${ }^{a}$ Formal home care model estimated among the elderly living in the community.

${ }^{\mathrm{b}}$ Simultaneous probit estimated by the Maximum Simulated Likelihood, using 10 pseudo-random draws per equation.

${ }^{c}$ At baseline in 1993, the survey participants were all residing in the community. To achieve convergence of the model, the reference wave for the nursing home model is set to 1993/1995.

${ }^{\mathrm{d}}$ Correlation of the error terms of the main equation and the likelihood of co-residing with an adult child, after adjusting for the simultaneity of the outcomes.

${ }^{\mathrm{e}}$ Correlation of the error terms of the main equation and the likelihood of co-residing with an adult child within 2 years of death after adjusting for the simultaneity of the outcomes.

Standard errors are in parentheses. They are obtained by 500 bootstrap iterations. Significant at $* * * 1 \%, * * 5 \%, * 10 \%$.

Table IV. Overall effect of proximity to death

\begin{tabular}{|c|c|c|c|c|}
\hline \multirow{2}{*}{ Type of care } & \multicolumn{2}{|c|}{ Mean predicted probabilities ${ }^{\text {ab }}$} & \multicolumn{2}{|c|}{ Marginal effect of proximity to death } \\
\hline & Do not die in 2 years & Die in 2 years & Percentage points & Relative increase \\
\hline Nursing home & $\begin{array}{l}4.01 \\
{[3.94,4.09]}\end{array}$ & $\begin{array}{l}6.03 \\
{[6.01,6.05]}\end{array}$ & $\begin{array}{l}2.02^{* * *} \\
{[1.92,2.12]}\end{array}$ & $50.37 \%$ \\
\hline Formal home care & $\begin{array}{l}7.01 \\
{[6.98,7.40]}\end{array}$ & $\begin{array}{l}7.88 \\
{[7.75,8.01]}\end{array}$ & $\begin{array}{l}0.87^{* * *} \\
{[0.71,1.03]}\end{array}$ & $12.41 \%$ \\
\hline
\end{tabular}

${ }^{\text {a}}$ Point-in-time probabilities: any use at the time of interview.

'The probabilities are predicted holding constant other participants' characteristics (including marital status and co-residence with an adult child) and are averaged over the entire sample.

In brackets are the $95 \%$ confidence intervals based on 500 bootstrap iterations. ${ }^{* * *}$ Marginal effect significant at $1 \%$.

likelihood of nursing home use is $4.0 \%$ not close to death and rises to $6.0 \%$ with proximity to death. This 2.0 percentage point increase means that the likelihood of institutionalization rises by about $50 \%$ in the last 2 years of life. Among community-based elderly, the probability of formal home care use starts at $7.0 \%$ and goes up to nearly $7.9 \%$ in the last 2 years of life. Such an increase corresponds to a relative marginal effect of $12.4 \%$.

In comparison, the marginal effect of age, defined as an increase of 1 year in age, is smaller (Table V). At age 80 , the marginal effect of age on institutionalization is about $4.8 \%$, and at age 90 it is $2.6 \%$ (relative increase). The effect of age is smaller for formal home care use, with a relative marginal increase of $1.6 \%$ at age 80 and $1.1 \%$ at age 90 . These results indicate that holding disability constant, both age and proximity to death affect the likelihood of long-term care use, but the effect of proximity to death is larger than the effect of age. It would take more than 10 years to get an effect of age similar to the effect of entering into the last 2 years of life. 
Table V. Effect of age

\begin{tabular}{|c|c|c|c|c|}
\hline \multirow[b]{2}{*}{ Type of care } & \multicolumn{2}{|c|}{ Mean predicted probabilities ${ }^{\mathrm{ab}}$} & \multicolumn{2}{|c|}{ Marginal effect of age } \\
\hline & Age & Age +1 & Percentage points & Relative increase \\
\hline \multicolumn{5}{|l|}{ Nursing home } \\
\hline Age $=80$ & $\begin{array}{l}4.18 \\
{[4.11,4.26]}\end{array}$ & $\begin{array}{l}4.38 \\
{[4.31,4.46]}\end{array}$ & $\begin{array}{l}0.20^{* * *} \\
{[0.20,0.20]}\end{array}$ & $4.78 \%$ \\
\hline Age $=90$ & $\begin{array}{l}6.07 \\
{[6.04,6.10]}\end{array}$ & $\begin{array}{l}6.23 \\
{[6.18,6.27]}\end{array}$ & $\begin{array}{l}0.16^{* * *} \\
{[0.14,0.18]}\end{array}$ & $2.64 \%$ \\
\hline \multicolumn{5}{|l|}{ Formal home care } \\
\hline Age $=80$ & $\begin{array}{l}6.94 \\
{[6.93,6.95]}\end{array}$ & $\begin{array}{l}7.05 \\
{[7.04,7.06]}\end{array}$ & $\begin{array}{l}0.11^{* * *} \\
{[0.10,0.12]}\end{array}$ & $1.59 \%$ \\
\hline Age $=90$ & $\begin{array}{l}7.88 \\
{[7.83,7.92]}\end{array}$ & $\begin{array}{l}7.95 \\
{[7.90,7.99]}\end{array}$ & $\begin{array}{l}0.07 * * * \\
{[0.07,0.07]}\end{array}$ & $1.14 \%$ \\
\hline
\end{tabular}

${ }^{\text {a }}$ Point-in-time probabilities: any use at the time of interview.

'The probabilities are predicted holding constant other participants' characteristics (including marital status and co-residence with an adult child) and are averaged over the entire sample.

In brackets are the $95 \%$ confidence intervals based on 500 bootstrap iterations. $* * *$ Marginal effect significant at $1 \%$.

\subsection{Effect of proximity to death by sources of informal care}

Table VI reports that the probabilities of institutionalization and formal home care use are lower when informal support is available to the elderly (i.e. among married and co-residing individuals) than among non-married elderly. For example, non-married elderly are about five times more likely to be institutionalized than co-residing elderly, whether or not close to death. These results support the assumption of substitution between formal and informal care.

When focusing on the marginal effect of proximity to death on nursing home use, we observe three phenomena (Table VI). First, as hypothesized, availability of informal care mitigates the effect of proximity to death. The largest effect of proximity to death is among non-married elderly: the probability of nursing home use increases, in relative terms, by nearly $75 \%$ in the last 2 years of life. As indicated by the absence of overlap in the $95 \%$ confidence intervals, the marginal effects of proximity to death for non-married elderly significantly differ from the effect for married or persons co-residing with an adult child. Second, among married elderly, proximity to death does not increase nursing home use significantly. Proximity to death is significant among non-married and co-residing elderly only. Third, the marginal effect of proximity to death is larger among elderly who co-residing with an adult child (relative increase of $39.4 \%$ ), than among married persons (relative increase of $2.1 \%$ ).

When considering formal home care use, we find that the effect of proximity to death is significant for all three groups, with the largest effect among non-married elderly. The probability of formal home care use increases by $15.5 \%$ in relative terms in the last 2 years of life. However, the effect of proximity to death does not differ significantly by sources of informal care, with a relative increase ranging from nearly $9 \%$ among married elderly to $11.3 \%$ among co-residing elderly.

\subsection{Robustness of results to measure of proximity to death}

In the results presented above, proximity to death is defined as 'being within 2 years of death'. To observe whether our results are sensitive to this measure, we run the same models using a shorter indicator of time to death, i.e. 'being within 1 year of death', and its interaction with being married and co-residing with an adult child. In that case, the sample is smaller. The deceased individuals without a date of death have to be dropped as the vital status of the next interview occurring in 2 years cannot be used $(n=991)$. Both measures of proximity to death provide comparable results, with modest differences described below.

In the nursing home model, availability of informal care has a larger mitigating effect for persons within 1 year of death than within 2 years of death. In the last year of life, the probability of 
Table VI. Effect of proximity to death by availability of informal care

\begin{tabular}{|c|c|c|c|c|}
\hline \multirow[b]{2}{*}{ Type of care } & \multicolumn{2}{|c|}{ Mean predicted probabilities ${ }^{\mathrm{ab}}$} & \multicolumn{2}{|c|}{ Marginal effect of proximity to death } \\
\hline & Do not die in 2 years & Die in 2 years & Percentage points & Relative increase \\
\hline \multicolumn{5}{|l|}{ Nursing home } \\
\hline Non-married ${ }^{\mathrm{c}}$ & $\begin{array}{l}5.07 \\
{[5.04,5.11]}\end{array}$ & $\begin{array}{l}8.84 \\
{[8.78,8.90]}\end{array}$ & $\begin{array}{l}3.77^{* * *} \\
{[3.74,3.80]}\end{array}$ & $74.36 \%$ \\
\hline Married $^{\mathrm{c}}$ & $\begin{array}{l}2.42 \\
{[2.22,2.62]}\end{array}$ & $\begin{array}{l}2.47 \\
{[2.40,2.53]}\end{array}$ & $\begin{array}{l}0.05 \\
{[-0.21,0.32]}\end{array}$ & $2.07 \%$ \\
\hline Reside $\mathrm{w} /$ child $^{\mathrm{c}}$ & $\begin{array}{l}1.09 \\
{[1.06,1.11]}\end{array}$ & $\begin{array}{l}1.52 \\
{[1.45,1.60]}\end{array}$ & $\begin{array}{l}0.43^{* * *} \\
{[0.34,0.52]}\end{array}$ & $39.45 \%$ \\
\hline \multicolumn{5}{|l|}{ Formal home care } \\
\hline Non-married ${ }^{\mathrm{c}}$ & $\begin{array}{l}7.72 \\
{[7.68,7.76]}\end{array}$ & $\begin{array}{l}8.92 \\
{[8.87,8.97]}\end{array}$ & $\begin{array}{l}1.20^{* * *} \\
{[1.11,1.29]}\end{array}$ & $15.54 \%$ \\
\hline Married $^{\mathrm{c}}$ & $\begin{array}{l}5.94 \\
{[5.91,5.96]}\end{array}$ & $\begin{array}{l}6.47 \\
{[6.23,6.71]}\end{array}$ & $\begin{array}{l}0.53^{* * *} \\
{[0.27,0.80]}\end{array}$ & $8.92 \%$ \\
\hline Reside $\mathrm{w} /$ child $^{\mathrm{c}}$ & $\begin{array}{l}4.94 \\
{[4.91,4.97]}\end{array}$ & $\begin{array}{l}5.50 \\
{[5.28,5.73]}\end{array}$ & $\begin{array}{l}0.56^{* * *} \\
{[0.31,0.82]}\end{array}$ & $11.34 \%$ \\
\hline
\end{tabular}

${ }^{a}$ Point-in-time probabilities: any use at the time of interview.

'The probabilities are predicted holding constant other participants' characteristics and are averaged over the entire sample. For example, when predicting by marital status, co-residence with an adult child is held constant, and vice versa.

${ }^{\mathrm{c}}$ Marital status and co-residence with an adult child are not mutually exclusive categories.

In brackets are the $95 \%$ confidence intervals based on 500 bootstrap iterations. $* * *$ Marginal effect significant at $1 \%$.

institutionalization diminishes among married and co-residing elderly; in comparison, being within 2 years of death has no effect among married elderly and as a small positive effect among co-residing persons. In the formal home care model, the effect of being within 1 year of death is similar in magnitude to being within 2 years of death but is not significant. In addition, being within 1 year of death (compared with 2 years) has a larger positive effect for married and co-residing elderly. This sensitivity analysis does not raise any concerns on our main results, but suggests that proximity to death may have nonlinear effects in the last months of life.

\section{DISCUSSION}

The results of this study have several methodological and policy implications. Both age and proximity to death are significant predictors of long-term care use. Formal long-term care use increases with age at a decreasing rate. Such nonlinear effects of age may be due to selection bias; those who survive to age 80 or 90 without yet being in a nursing home are just less likely ever to use nursing home care. Holding other characteristics of the elderly population constant, increasing longevity will raise to some extent the per capita demand for long-term care.

Another related implication is that the degradation in health attributable to mortality (captured by proximity to death) has a distinct effect from the morbidity process (measured by disability and cognition) and aging itself. The studies that disentangle the morbidity and mortality processes also find independent effects of these two dimensions (Cutler and Sheiner, 1998; Cutler and Meara, 2001; Seshamani and Gray, 2004a,b; Werblow et al., 2007; Stearns et al., 2007). However, because age is also a significant determinant of long-term care use, all three dimensions of health need to be considered to accurately estimate participation in the long-term care market.

This study is the first to document the interplay between two major determinants of long-term care use: proximity to death and sources of informal support. On one hand, proximity to death has a large positive effect among non-married elderly, who constitute the vast majority of the frail elderly population. On the other hand, proximity to death plays a smaller role for the elderly co-residing with an adult child, and even a smaller or non-significant role among married elderly. As mentioned earlier, 
a few studies reveal that spousal care may be a more likely substitute for formal care than help from children (Freedman, 1996; Newman and Struyk, 1990). Our results confirm this phenomenon, as the mitigating effect on proximity to death is larger for being married than co-residing with an adult child. Such findings are important in the context of changing informal support. The increase in the proportion of married elderly observed over the last decade (CPS, 2007) indicates that availability of spousal care has increased among the $70+$ population. Therefore, in the future, the total effect of proximity to death may lessen if spousal care continues to become more prevalent. Even if spousal care substitutes for help from children, the contribution of proximity to death in shaping the demand for institutionalization will be reduced because proximity to death is not significant among married elderly, but is significant among individuals co-residing with adult children. More broadly, this study documents that changes in informal support interplay with health status and that the effect of health should not be considered separately from the effect of availability of informal care.

In this study, one advantage of measuring proximity to death by one dichotomous indicator is that it limits the number of interaction terms. Doing so facilitates the use of an instrumental variable strategy to address the endogeneity of co-residence with an adult child by limiting the number of required valid instruments (i.e. overidentification). However, a set of indicators could capture nonlinear effects of proximity to death and help determine more specific patterns of long-term care use in the months of life. As shown in studies on acute and overall health-care expenditures, effects during the last few months before death may be especially strong and would deserve some attention in future works on long-term care (Zweifel et al., 1999; Seshamani and Gray, 2004a). Furthermore, proximity to death is likely to affect the quality, hours and expenditures devoted to long-term care, and such outcomes may also differ by types of informal support available to the elderly. In addition, it may be important to understand whether the interplays of proximity to death and sources of informal care differ by racial and ethnic groups because African Americans and Hispanics constitute an increasing proportion of the elderly population in the United States (Administration on Aging, 2003).

One unsolved methodological issue is the potential endogeneity of proximity to death (Salas and Raftery, 2001). However, as explained in the method section, our simultaneous probit models provide conservative estimates: adjusting for individual FE in linear probability models increased the magnitude of the coefficients of interest but did not change their significance level. In total, the endogeneity of proximity to death may be more problematic for acute care than long-term care use, and further efforts are needed to find valid instruments.

There is ample evidence that marital status is a major determinant of long-term care use as the presence of a spouse is in general consider as a source of informal care (Cutler and Sheiner, 1998; Stearns et al., 2007). However, this variable may potentially include some measurement error due to the fact that some spouses may be sick and unable to provide care. Such phenomenon is likely to be random and therefore may not bias our estimates.

The present model reveals the distinct role of proximity to death, age and disability, when controlling for the other determinants of long-term care use. While the model helps identify the separate role of these three dimensions of health, a more simplified model that does not control for all the determinants might be required for health-care expenditure predictions. In particular, it may be difficult to forecast disability. Two studies have used such simplified model to project future Medicare expenditures, using age and proximity to death to capture disability (Miller, 2001; Stearns and Norton, 2004). Such forecasting is beyond the scope of the present study.

Increasing attention is being paid to the respective effects of aging and technology changes on health-care expenditures (Dormont et al., 2006; Cutler, 2005; OECD, 2006). Beside age, proximity to death and informal care, future works should also consider the effect of technology on long-term care use, even if technology improvements are much more limited in long-term care than acute care services. 


\section{CONCLUSIONS}

Our findings have three implications for policy. As proximity to death is a major driver of the likelihood of long-term care use, such measures need to be incorporated in models to accurately describe the demand for long-term care. Second, the likelihood of long-term care use does increase with age. As a result, increasing longevity alone will raise to some extent long-term care expenditures. Finally, the effect of proximity to death is significantly mitigated by availability of informal care. The participation in the long-term care market is not as concentrated at the end of life for married elderly and those coresiding with adult children, as it is for non-married elderly. Such findings indicate that it may be possible to control the increase in future long-term care use at the end of life by promoting the provision of informal care.

\section{ACKNOWLEDGMENTS}

Our thanks go to Frank Sloan, Willard Manning, Peter Kemper and Peggy Dilworth-Anderson for helpful comments during the course of this study. We also want to thank the participants at the inaugural ASHE conference in Madison and the Health Service Research Colloquium at The Pennsylvania State University, in particular John Moran and Pamela Farley Short. This research was funded by the Swiss Science Foundation, grant number PBSK1-106659. Additional support was provided by the Demography and Economics of Aging Research Group at The University of North Carolina at Chapel Hill, grant number NIA P30 AG024376.

\section{CONFLICT OF INTEREST}

None.

\section{ETHICS}

IRB approval from the School of Public Health at The University of North Carolina.

\section{REFERENCES}

Administration on Aging (AoA), US Department of Health and Human Services. 2003. 'Facts and figures' statistics on minority aging in the US. (Available from: http://www.aoa.gov/prof/statistics/minority_aging/facts_minority_aging.asp on September 2003.)

Ai C, Norton EC. 2003. Interaction terms in logit and probit models. Economics Letters 80: 123-129.

Bhattacharya J, Goldman D, McCaffrey D. 2006. Estimating probit models with self-selected treatments. Statistics in Medicine 25: 389-413.

Cappellari L, Jenkins SP. 2006. Calculation of multivariate normal probabilities by simulation, with applications to maximum simulated likelihood estimation. The Stata Journal 6: 156-189.

Carmichael F, Charles S. 2003. The opportunity costs of informal care: does gender matter? Journal of Health Economics 22: 781-803.

Charles KK, Sevak P. 2005. Can family caregiving substitute for nursing home care? Journal of Health Economic 24: 1174-1190

Checkovich TJ, Stern S. 2002. Shared caregiving responsibilities of adult siblings with elderly parents. Journal of Human Resources 37: 441-478.

Current Population Survey (CPS). 2007. America's families and living arrangements. (Available from: http:// www.census.gov/population/www/socdemo/hh-fam.html on July 2007.)

Cutler DM. 2005. The potential for cost savings in Medicare's future. Health Affairs, Web Exclusive, September 26, 2005. (Available from: http://content.healthaffairs.org.) 
Cutler DM, Meara E. 2001. The concentration of medical spending, an update. In Themes in the Economics of Aging, Wise DA (ed.). The University of Chicago Press: Chicago; 217-240.

Cutler DM, Sheiner L. 1988. Demographics and medical care spending: standard and non-standard effects. NBER Working Paper 6866, 1998. (Available from: htpp:||www.nber.org/papers/w6866 on October 2004.)

Dormont B, Grignon M, Huber H. 2006. Health expenditure growth: reassessing the threat of ageing. Health Economics 15: 947-963.

Felder S, Meier M, Schmitt H. 2000. Health care expenditures in the last months of life. Journal of Health Economics 19: 679-695.

Freedman V. 1996. Family structure and the risk of nursing home admission. The Gerontologist 51B: S61-S69.

Greene WH. 2003. Econometric Analysis (5th edn). Prentice-Hall, Pearson Education Inc: Upper Saddle River.

Lakdawalla D, Goldman DP, Bhattacharya $\mathbf{J}$ et al. 2003. Forecasting the nursing home population. Medical Care 41: $8-20$.

Lo Sasso AT, Johnson RW. 2002. Does informal care from adult children reduce nursing home admissions for the elderly? Inquiry 39: 279-297.

Lubitz J, Beebe J, Baker C. 1995. Longevity and Medicare expenditures. New England Journal of Medicine 332: 999-1003.

Lubitz J, Cai L, Kramarow E, Lentzner H. 2003. Health, life expectancy, and health care spending among the elderly. New England Journal of Medicine 349: 1048-1055.

Manton KG. 2003. Forecasting the nursing home population. Medical Care 41: 21-24.

Manton KG, Stallard E, Corder LS. 1998. The dynamics of dimensions of age-related disability 1982 to 1994 in the US elderly population. Journal of Gerontology, Biological Sciences 53A: B59-B70.

Miller T. 2001. Increasing longevity and Medicare expenditures. Demography 38: 215-226.

National Center for Health Statistics (NCHS).2003. National Vital Statistics Report 2003. (Available from: http:// www.cdc.gov/nchs/products/pubs/pubd/nvsr/nvsr.htm on October 2006.)

Newman SJ, Struyk R. 1990. Overwhelming odds: caregiving and the risk of institutionalization. Journal of Gerontology, Social Sciences 45: S173-S183.

Norton EC. 2000. Long-term care. In Handbook of Health Economics, Culyer AJ, Newhouse JP (eds). Elsevier Science B.V.: New York, NY; 956-994.

Norton EC, Wang H, Ai C. 2004. Computing interaction effects and standard errors in logit and probit models. The Stata Journal 4: 154-167.

OECD. 2006. Projecting OECD health and long-term care expenditures: what are the main drivers? Economics Department Working Papers.

Payne G, Laporte A, Deber R, Coyte PC. 2007. Counting backward to health care's future: using time-to-death modeling to identify changes in end-of-life morbidity and the impact of aging on health care expenditures. The Milbank Quarterly 85: 213-257.

Pezzin LE, Schone BS. 1999. Parental marital disruption and intergenerational transfers: an analysis of lone elderly parents and their children. Demography 36: 287-297.

Rivers D, Vuong QH. 1988. Limited information estimators and exogeneity tests for simultaneous probit models. Journal of Econometrics 39: 347-366.

Salas C, Raftery J. 2001. Econometrice issues in testing the age neutrality of health care expenditures. Health Economics 10: 669-671.

Seshamani M, Gray A. 2004a. Ageing and health-care expenditures: the red herring argument revisited. Health Economics 13: 303-314.

Seshamani M, Gray A. 2004b. A longitudinal study of the effects of age and time to death on hospital costs. Journal of Health Economics 23: 217-235.

Spector WD, Fleishman JA, Pezzin LE, Spillman BC. 2000. The characteristics of long-term care users. AHRQ Publication No. 00-0049.

Spillman BC, Lubitz J. 2000. The effect of longevity on spending for acute and long-term care. New England Journal of Medicine 342: 1409-1415.

Spillman BC, Lubitz J. 2002. New estimates of lifetime nursing home use. Have patterns of use changed? Medical Care 40: $965-975$.

Spillman BC, Pezzin LE. 2000. Potential and active family caregivers: changing networks and the 'sandwich generation'. Milbank Quarterly 78: 347-374.

Stearns SC, Norton EC. 2004. Time to include time to death? The future of health care expenditure predictions. Health Economics 13: 315-327.

Stearns SC, Norton EC, Yang Z. 2007. How age and disability affect long-term care expenditures in the United States. Social Policy and Society 6: 1-11 
Van Houtven CH, Norton EC. 2004. Informal care and health care use of older adults. Journal of Health Economics 23: $1159-1180$.

Van Houtven CH, Norton EC. 2008. Informal care and Medicare expenditures: testing for heterogeneous treatment effects. Journal of Health Economics 27: 134-156.

Werblow A, Felder S, Zweifel P. 2007. Population ageing and health care expenditures: a school of 'red herrings'? Health Economics 16: 1109-1126.

Wooldridge JM. 2002. Econometric Analysis of Cross Section and Panel Data. The MIT Press: Cambridge MA.

Yang Z, Norton EC, Stearns SC. 2003. Longevity and health care expenditures: the real reasons older people spend more. Journal of Gerontology, Social Sciences 58B: S2-S10.

Zweifel P, Felder S, Meiers M. 1999. Aging of population and health care expenditures: a red herring?. Health Economics 8: 485-496.

Zweifel P, Felder S, Werblow A. 2004. Population ageing and health care expenditure: new evidence on the 'red herring'. The Geneva Papers on Risk and Insurance 29: 652-666. 